\title{
Experimental Examination on the Effect of Composite Amalgam with Fly ash \& E-glass Materials with Al-8011Subjected to Mechanical Characterization
}

\author{
Ghadge S.S, Balappa B. Hadagali, S A Mohan Krishna, G V Naveen Prakash, K B Vinay, K S Ravi
}

\begin{abstract}
The main objective of this experimental examination is to accentuate the salient effect of mixtures viz., E-glass and Fly ash based on the characterization of prominent mechanical properties of Al 8011 hybrid amalgamated composites. The prominent alloy Al-8011 amalgamated with particulates of E-glass and fly ash materials have been fabricated by using graphite die for the method of casting. The metal matrix composite is fabricated for dissimilar configuration of the particulates of E-glass and fly-ash by changing E-glass with constant fly ash. The hybrid composite samples have been fabricated as per genuine prerequisite of ASTM standards or conditions to accomplish pertinent tensile and compression tests.
\end{abstract}

Keywords: E-glass, Al8011, Fly-ash, Metal matrix composites.

\section{INTRODUCTION}

Metal matrix composites (MMCs) have revealed better mechanical properties of strength, magnitude of specific modulus, value of restraining capacity and virtuous wear resistance characteristic when compared to the unreinforced alloys. The composite materials are exceedingly resulting its enormous application because of lower magnitude of density and lower cost factor of reinforcement or amalgam obtainable viz., fly ash, fly ash is vastly accessible in the process of coal burning at steam or thermal power plants [15].

In a metal matrix composite, the matrix phase is a low density nonferrous alloy which is monolithic in nature. The reinforcement comprises carbon and additions of metallic or ceramic materials. Reinforced compounds which are principally inter-metallic, viz., metals titanium, nickel and iron aluminides are in the embryonic phase. "Continuous fibre or filament reinforcements comprise the reinforcements or amalgams viz., Graphite (Gr), Silicon Carbide (SiC), Boron, Aluminium Oxide $\left(\mathrm{Al}_{2} \mathrm{O}_{3}\right)$ and refractory materials.

Revised Manuscript Received on December 5, 2019.

Ghadge S.S, Department of Mechanical Engineering, SGOI, COE,Pune Email: subhodh85@gmail.com

Balappa B. Hadagali, Department of Mechanical Engineering, SGOI, COE,Pune.

S A Mohan Krishna, Department of Mechanical Engineering, VVCE, Mysuru.

G V Naveen Prakash, Department of Mechanical Engineering, VVCE, Mysuru.

K B Vinay, Department of Mechanical Engineering, VVCE, Mysuru.

Dr. K S Ravi, Department of Mechanical Engineering, VVCE, Mysuru.
Discontinuous reinforcements consist of mainly Silicon Carbide in whisker form and Silicon Carbide, Aluminium Oxide and Titanium Dioxide in particulate category and short or chopped fibres of Aluminium Oxide or Graphite [1]." Particle reinforced composites have reasonably enhanced isotropic properties when compared to whisker reinforced composites.

\section{A. Hybrid Composite}

Aluminium Silicon Carbide composites (Al SiCp) are regarded as the most advantageous composites because of their supreme mechanical and thermal properties. Aluminium reinforced or amalgamated Silicon Carbide particulate composite materials are finding all-embracing engineering applications predominantly in industrial sector. The major advantages by employing Silicon Carbide as reinforcement are improved stiffness property, strength factor, magnitude of thermal conductivity, wear resistance property, fatigue resistance, low cost, value of low density and magnitude of low thermal expansivity. Besides these unique properties, they are comparatively easier to fabricate and have shown greater potential to be inexpensive. Aluminium Silicon Carbide particulate composites are one of the promising materials that find expansive applications in automobile and aeronautical engineering. Fig. 1 gives the detail about the classification.

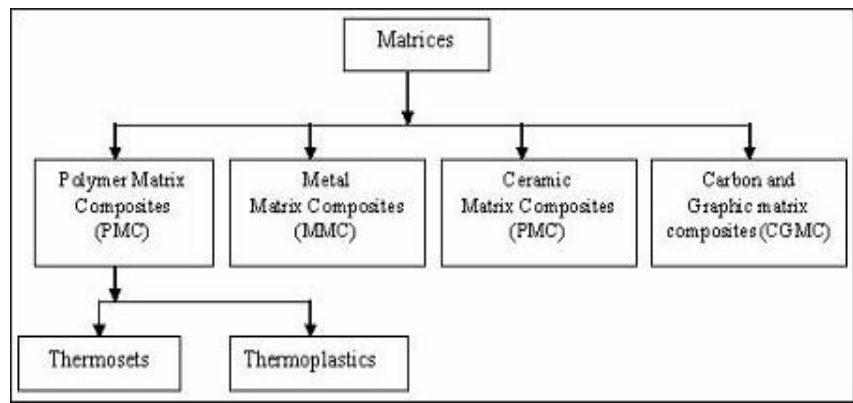

Fig.1. Classification of Matrix Materials

\section{B. Metal Matrix Composites}

MMCs, presently though engendering a varied attention in the area of exploration but are not extensively used as their plastic equivalents. "They can endure with greater value of temperature in eroding environment when compared to polymer composite materials.

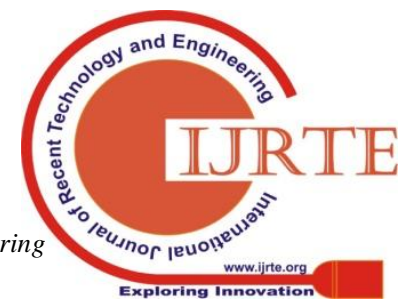
\& Sciences Publication 
Many metals and alloys con be employed as matrices but they necessitate reinforcement materials which can be unwavering over an assortment of temperature should be non-reactive too." The properties based on physical and mechanical behaviour of the specified composite at diverse range of temperatures that regulate the package or overhaul temperature of composites. Furthermost of the metals, ceramics and compounds could be employed with matrices of low-slung range of peak of melting of alloys. The adding of reinforcements or amalgam to the matrix material be contingent with the anticipated properties and applications. The sundry demand framework of reinforcements of metal matrix composites is established by fabrication and dispensation and by the matrix arrangement of the composite [2].

The prospective of metal matrix composites for significant improvements in performance over conventional alloys have received good recognition [1-10]. The uniform distribution of the reinforcements is extremely important for materials characterization, without which the properties and quality of a composite material gets affected $[1,2,3]$. In this chapter, the importance of MMCs, their classification, advantages and applications have been emphasized. Also, the method of fabricating AMCs required for experimentation has been discussed. The following section presents an overview of metal matrix materials.

\section{Particulate Reinforced Composites}

The transformation among particulate composite and diffusion strengthened ones is, thus, oblivious and the contrivance employed to fortify is also diverse [11 - 20]. The production techniques, thermal and mechanical properties essentially depend on the exceptionality of these composite materials which are generally characterized by their microstructure and interfaces. The microstructure designates the prearrangement of the matrix and the reinforced stage. Some of the attributes viz., chemical composition, grain, uniformity, behaviour and imperfections in the lattice are imperative for the matrix. After the addition of reinforcements, the resulting composite can be categorized based on the volume, variety, size, distribution and point of reference [2]. In particular, many of the reflections arising due to the technique of fabrication, processing capabilities and serviceability of composites have been associated unequivocally to the metallurgical characteristics that take place in the interfacial region betwixt matrix and reinforcement $[3,6]$.

The prospective of metal matrix composites for substantial progresses in presentation over conventional alloys have received good appreciation. The advantage of using composites is to accomplish property combinations that can result in a number of amenity benefits [1-12]. This is due to copious technical tasks that exist with casting technology, which can be addressed effectually. The uniform distribution of the reinforcements is extremely essential for materials characterization, without which the properties and quality of a composite material gets affected [1, 2, 3].

\section{METHODOLOGY}

"The matrix material for this experimental investigation is commercially aluminium alloy Al 8011 ingot, fly ash and e-glass materials. The hybrid or amalgamated composite materials have been fabricated by stir casting technique.The diverse percentage conformations of hybrid composite specimens by weight percentage proportions of Al 8011, fly ash and e-glass materials. Pure commercial aluminium ingot $\mathrm{Al} 8011$ is heated in a robust electric furnace at $750 \mathrm{oC}$ for nearly two hours duration in a receptacle containing Graphite. Then the melted component has been stirred completely for two minutes with the adding of fly ash, e-glass material conformations which are weighed, hexachlorine ethane tablets."

\section{Casting process}

\section{A. Stir Casting}

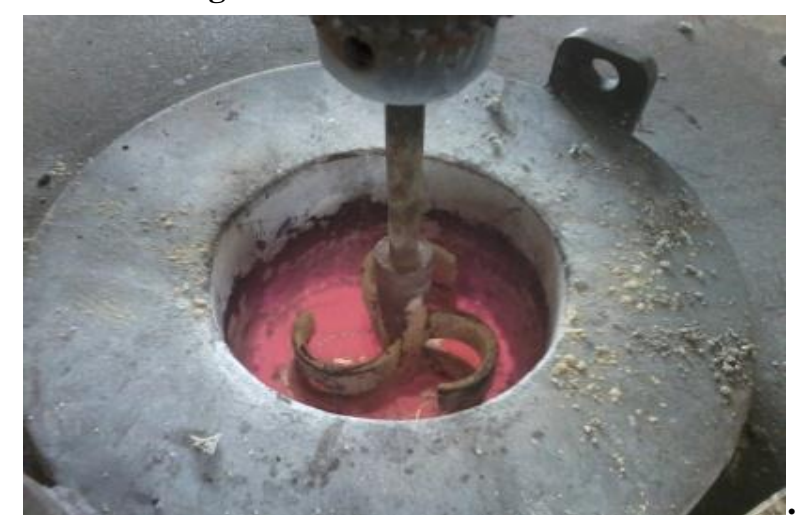

Fig. 2. Stir Casting Process.

In the progression of stir casting, the phases of reinforcements are to be disseminated into the matrix of molten state by the action of stirring by mechanical means. In stir casting technique, the process of stirring in the furnace has been regarded as the most dominating component. The resultant melted alloy with ceramic elements can then be used for the die casting. Stir casting has been best suited for the process of manufacturing composite materials with up to the percentage of volume fraction of $30 \%$ of the reinforcements. The composite materials accomplished by the process of casting are further extruded to lessen the amount of porosity, refinement of microstructure and normalize the dissemination of the reinforcements [14 - 19] "The process of preheating of the particles of Silicon Carbide leads to the artificial oxidation of the particle surface forming Silicon dioxide $\left(\mathrm{SiO}_{2}\right)$. This layer helps in progressing the stuff of wettability of the particle."

\section{B. Casting Of Different Composition of Hybrid Composites}

The composites with changing percentage compositions have been prepared by maintaining proper content of fly-ash and e-glass with varying proportions. The first four succeeding mixture composite samples have been fabricated by maintaining $2 \%$ fly-ash proportion and varying the proportion of e-glass

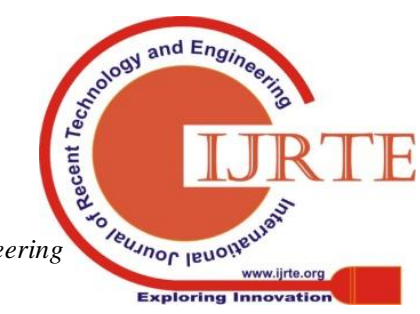


composition $1 \%, 3 \%, 5 \%, 7 \%$ proportions hooked on Al-8011 melt process. The above emphasized procedure has been recurrent in by maintaining fly-ash content continuous for $4 \%, 6 \%$ and $8 \%$.

\section{RESULTS \& DISCUSSIONS}

\section{A. Tensile Test}

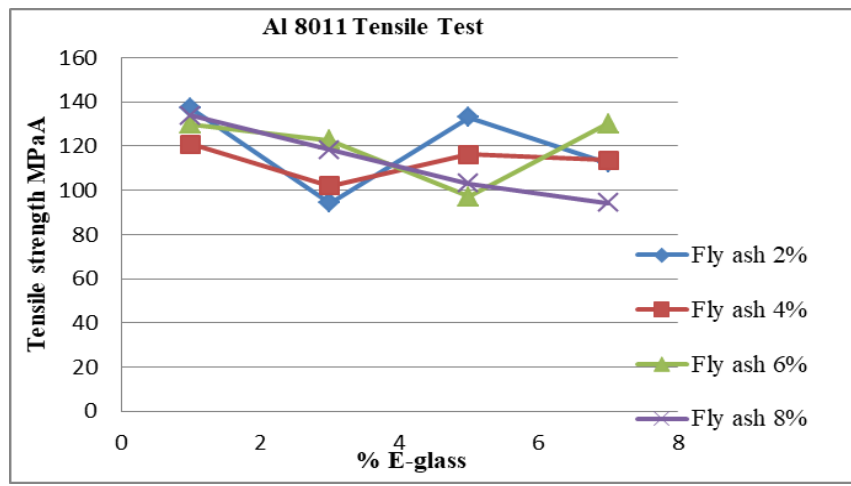

Fig.3. Comparison of Tensile strength of Hybrid Composites

Fig. 3 projects that, with varying percentage proportions of the content of fly ash and e-glass materials with Al 8011 alloy, it has been perceived that, as the proportion of fly ash upsurge the magnitude of tensile strength intensifies.

\section{B. Compression Test}

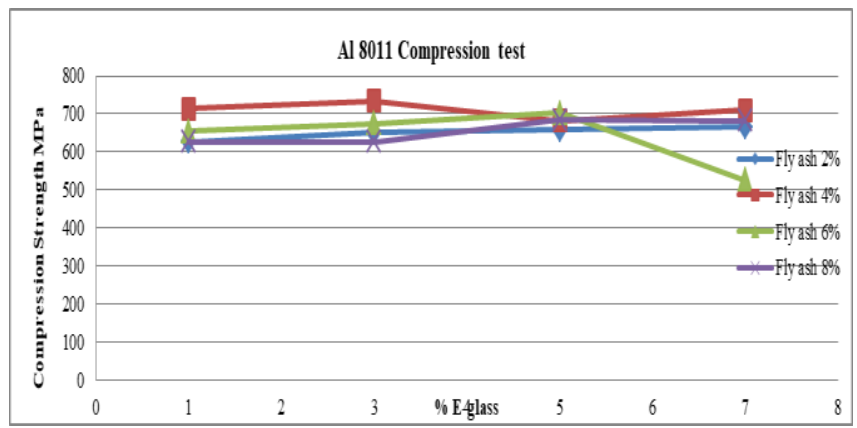

Fig.4. Comparison of compression strength of Hybrid Composites

Fig. 4 indicates that, with surge in proportion of fly ash and e-glass materials there has been intensification in the magnitude of strength based on compression. The optimum conformation to acquire extreme strength based on compression has originated to be $4 \%$ fly ash $3 \%$ e-glass.

\section{CONCLUSIONS}

\section{Tensile strength test:}

The magnitude of strength based on tension diminishes and tensile factor is thoroughgoing for fly-ash $2 \%$ E-glass $1 \%$. The value of tensile strength property is determined for fly-ash $4 \%$ and e-glass $3 \%$ compositions. For fly-ash 6\%: The experimental inferences of samples nine to twelve depict that with escalation in percentage of fly-ash and e-glass strength based on tensile factor attenuates.

\section{Compression Test:}

It can be observed that, based on compression test, for fly-ash $2 \%$, based on the augmentation in the proportions of e-glass, the magnitude of strength based on compressive factor gets augmented. Correspondingly, for fly-ash $4 \%$, the magnitude of strength based on compression is concentrated for the dissimilar fraction of fly-ash $4 \%$ and e-glass $3 \%$ materials. Aimed at the other ranging percentage of fly-ash $6 \%$, the experimental inferences of specimens nine to twelve depict that, with the upsurge in proportion of fly-ash and e-glass, métier based on compression diminishes and analogously for fly-ash $8 \%$, with escalation in the measurement of e-glass compressive strength have been declined."

\section{REFERENCES}

1. Shyong J.H et al, Materials Science \&Engineering A: Structural Materials; properties, Microstructure and processing, Vol.A197, N 1, Jun 301995 , pp. 11-18.

2. Cui Y Geng, journal of Materials Science Letters Vol. 16, N10, May 15 1997, pp.788-790.

3. Choonwengwong, Manoj Guptha, Lilu, journal of Material Sc. \&Tech vol. 20, Feb 2004.pp.34-42.

4. K.H.W. Seah., S.C Sharma, J of Alloys and Compounds Vol.306, 2000, pp. 270-276.

5. F.T. Wallenberger, Structural Silicate and Silica Glass Fibers, in Advanced Inorganic Fibers Processes, Structures, Properties, Applications, F.T. Wallenberger, Ed., Kluwer Academic Publishers, 1999, pp. 129-168

6. D.M. Miller, Glass Fibers, Composites, Vol 1, Engineered Materials Handbook, ASM International, 1987.

7. M.K. Surappa. 1979. PhD Thesis. Indian Institute of Sciences, Bangalore, India.

8. D.A. Koss, S.M. Coply. 1971. Metall. Trans. 24: 551.

9. W.J. Clegg. 1998. Acta Metall. 36: 1-73.

10. B.C. Pai, GeethaRamani, R.M. Pillai, K.G. Sathyanarayana. 1995. Role of Magnesium in cast Aluminium alloy matrix composites. Journal of Material Science. 30: 1903-1911.

11. C. Tekmen. 2003. The effect of $\mathrm{Si}$ and $\mathrm{Mg}$ on the age hardening behaviour of Al-Sic composites. Composite Materials.37 (20).

12. P.K. Rohatgi, J.K. Kim, N. Gupta, Simon Alaraj, A. Daoud. 2006 Compressive characteristics of A356/fly ash cenosphere composites synthesized by pressure infiltration technique. Composites: Part A. 37: 430-437.

13. Sudarshan M.K. Surappa. 2007. Synthesis of fly ash particle reinforced A356 Al composites and their characterization. Materials Science and Engineering A. 480 (2008) 117-124.

14. P.K. Rohatgi, R.Q. Guo, H. Iksan, E.J. Borchelt, R. Asthana. 1998 Pressure infiltration technique for synthesis of aluminum-fly ash particulate composite. Materials Science and Engineering A. 244: 22-30.

15. D.P. Mondal, S. Das, N. Ramakrishnan, K. UdayBhasker. 2009 Cenosphere filled aluminium syntactic foam made through stir-casting technique. Composites Part A: Applied Science and Manufacturing Volume 40, Issue 3, 279-288

16. D.P. Mondal, M.D. Goel, S. Das. 2009. Effect of strain rate and relative density on compressive deformation behaviour of closed cell aluminum-fly ash composite foam. Materials and Design. 30: 1268-1274.

17. A.K. Banerjee, P.K. Rohatgi, W. Reif. 1985. In: Proceedings of the eight symposiums in Advanced Materials Research and Development for Tansport-Composites. Stravsbourg, France. November.

18. D. Ramesh, R. P. Swamy and T. K. Chandrashekar. 2010. Effect of weight percentage on mechanical properties of frit particulate reinforced al6061 composite. ARPN Journal of Engineering and Applied Sciences. 5(1): 32-36

19. R. Q. Guo, P.K. Rohatgi, D. Nath. 1997. Preparation of aluminium-fly ash particulate composite by powder metallurgy technique. Journal of Materials Science. 32: 3971-3974.

20. H.B. Niranjan. 1998. Tensile and Corrosive properties of Al Haematite composite. In: Proceedings of the first Australasian Conference on Composite Materials (ACCM -I), Osaka Japan. 7-9 October. pp. 546. 


\section{AUTHORS PROFILE}

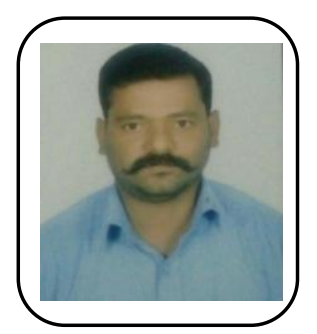

Prof. S S Ghadge is presently working as an assistant professor in one of the engineering institutions at Pune. He is the member for many professional bodies and has authored a book. To his credit, he has many research publications.

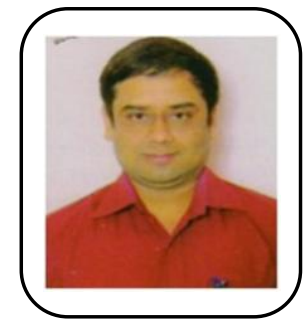

Rtn. Dr. S A Mohan Krishna completed Bachelor of Engineering from one of the prestigious institutions in Mysuru, Vidyavardhaka College of Engineering (VVCE) in 2003, M. Tech in Energy Systems from Sri Jayachamarajedra College of Engineering (SJCE), Mysuru in 2010, presently JSS University of Science \& Technology and completed $\mathrm{Ph} . \mathrm{D}$ from The National Institute of Engineering (NIE), Mysuru in 2017 on 'Thermal Characterization of Hybrid Metal Matrix Composites' belonging to the area of thermal engineering and computational materials science. Has published over 70 papers in peer reviewed international journals and has presented papers at Qatar and Singapore and also in various parts of Karnataka. He is in the editorial and reviewer board for nearly 40 reputed referred international journals including the most prominent namely Elsevier and Springer. He is a life member for many professional bodies. He is the recipient of NIE Gold Medal, Dr. Raj Achievement Technology Award, Bharataratna Sir M Visveshvaraya Achievement Award, Dr. A P J Abdul Kalam Achivement Award and Dr. S Radhakrishnan Education Award which have been conferred to him in the field of science, education, engineering and technology by various prestigious and premier associations.

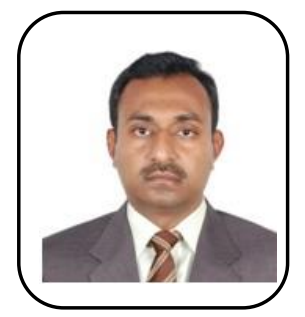

Dr. G.V. Naveen Prakash currently working as Professor \& HOD in the Department of Mechanical Engineering has more than 13 years of teaching and industrial experience. He joined VVCE in the year 2001 and has served the institution in various capacities. He completed his Bachelors of Engineering from P.E.S College of Engineering, Mandya in the year 1998. In the year 2001 he did his M.Tech in PEST from NIE, Mysore. He was awarded the degree of Doctor of Philosophy (Ph.D) in Faculty of Mechanical Engineering Sciences by Visvesvaraya Technological University, Belgaum in 2011. Dr. G.V. Naveen Prakash has published 33 technical papers in various National and International Journals and Conferences both in India and Abroad. He has organized/attended many workshops/Conference/Faculty Development Programme. He is life member of Indian Society of Technical Education (ISTE), The Institution of Engineers (India) - IE. He is also an active member of various committees in the institution. He is the member of Section Managing Committee of Indian Society of Technical Education (ISTE), Karnataka Section for 2012-2014. He has visited USA to present a technical paper in the ASME 2013 International Mechanical Engineering Congress \& Exposit.

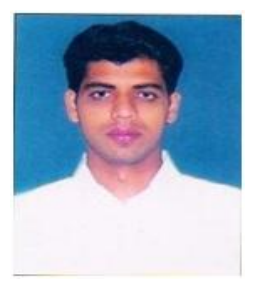

Dr. K B Vinay, Prof. Vinay K. B completed Bachelor of Engineering BE from PESCE Mandya in 2000, M. Tech in Engineering Management from Sri Jayachamarajedra College of Engineering (SJCE), Mysore in 2003 and pursuing Ph. D in Engineering Management at Sri Jayachamarajedra College of Engineering (SJCE), Mysore. Prof. Vinay K B joined as a Lecturer VVCE in 2005. He was promoted as Senior Lecturer in 2010 and Assistant Professor (Senior Scale) in 2011 and as Associate Professor in 2013, accentuating with overall experience in the institution for 11 years. His area of interest in teaching is mainly Management. He teaches Engineering System Design, Engineering Economics, Stastical Quality Control, Elements of Mechanical Engineering and Heat \& Mass Transfer, Computer Aided Engineering Drawing, Operations Management. He has presented more than 4 technical papers in international conferences and has published more than 5 Papers in International journals. He is life member of Indian Society of Technical Education (ISTE).

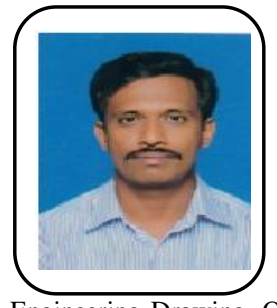

Prof. Ravi K S joined as a Lecturer in 1999. He was promoted as Senior Lecturer in the year 2008 and Assistant Professor (Senior Scale) in 2011, He was promoted as Associate Professor in 2013, accentuating with overall experience in the institution for 14 years. He teaches Control Engineering, Hydraulics \& Pneumatics, Engineering System Design, Management \& Entrepreneurship, Mechtronics \& Microprocessor, Engineering Drawing, Organization Behaviour, Industrial Management, and Cost Estimation \& Economics Engineering. He has presented more than 4 technical papers in international conferences, published in International journals and life member of Indian Society of Technical Education (ISTE), Also guided more than 20 UG \& PG students Projects. Member/coordinator in various committees in the organization. 